Convened by the Pacific Islands Climate Science Center, the Pacific Regional Integrated Sciences and Assessments Program, and the Pacific Islands Climate Change Cooperative

\title{
Report from the Workshop on Climate Downscaling and its Application in High Hawaiian Islands, September 16-17, 2015
}
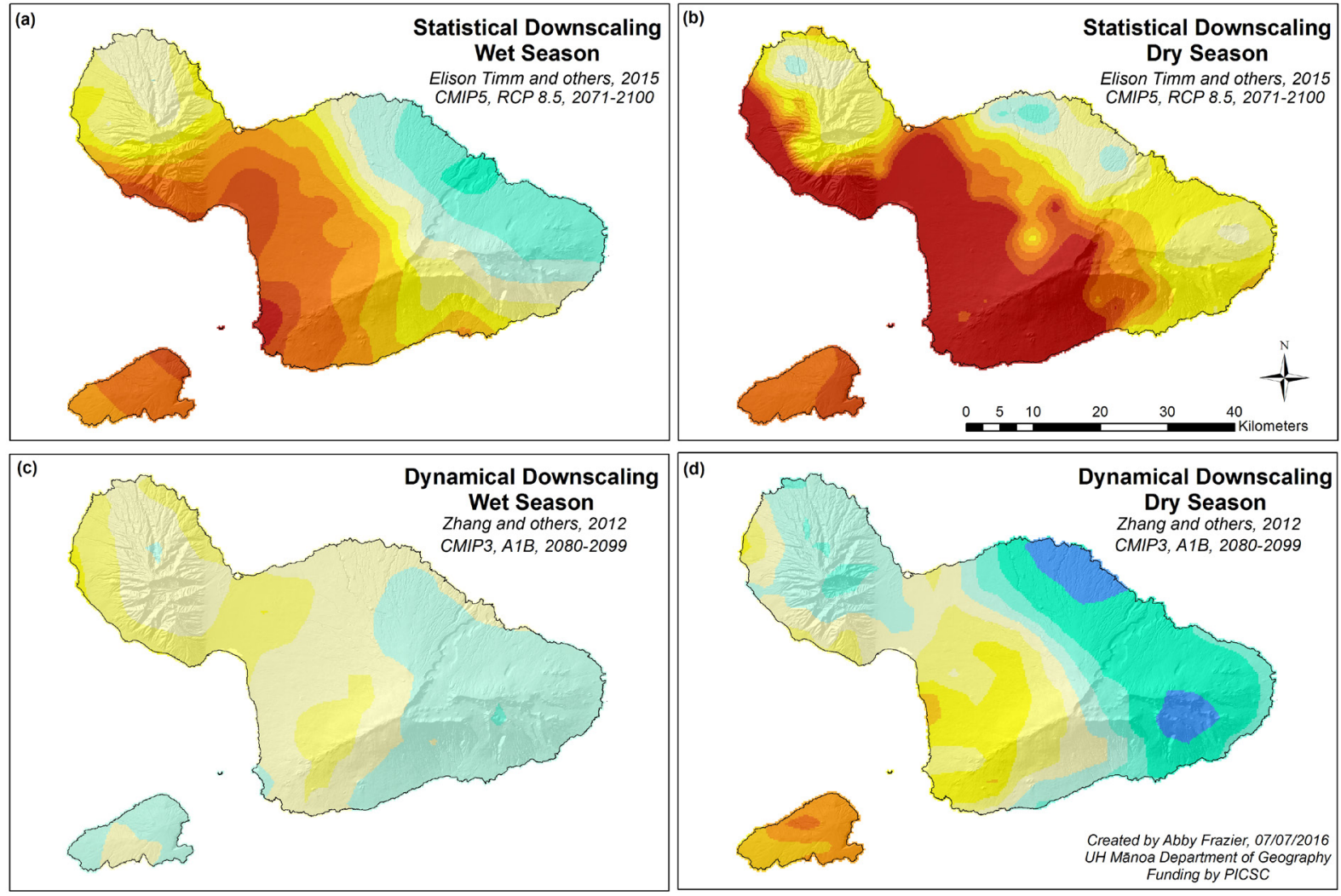

Open-File Report 2016-1102

U.S. Department of the Interior U.S. Geological Survey 
Cover: Maps showing downscaled projections of percent change in seasonal rainfall at the end of the 21st century on Maui and Kaho'olawe Islands. Maps $A$ and $B$ are based on statistical downscaling models; maps $C$ and $D$ are based on dynamical downscaling models. Percentages are displayed in a "rainbow" color spectrum that ranges from red (as much as $90 \%$ decrease in rainfall) through light yellow and green (minimal change) to blue (as much as $40 \%$ increase in rainfall). Figure prepared by Abby Frazier, University of Hawaii at Manoa. 


\section{Report from the Workshop on Climate Downscaling and its Application in High Hawaiian Islands, September 16-17, 2015}

By David A. Helweg, Victoria Keener, and Jeff M. Burgett

Open-File Report 2016-1102 


\section{U.S. Department of the Interior \\ SALLY JEWELL, Secretary}

\section{U.S. Geological Survey \\ Suzette M. Kimball, Director}

U.S. Geological Survey, Reston, Virginia: 2016

For more information on the USGS - the Federal source for science about the Earth, its natural and living resources, natural hazards, and the environment-visit http://www.usgs.gov or call 1-888-ASK-USGS (1-888-275-8747).

For an overview of USGS information products, including maps, imagery, and publications, visit http://store.usgs.gov.

Any use of trade, firm, or product names is for descriptive purposes only and does not imply endorsement by the U.S. Government.

Although this information product, for the most part, is in the public domain, it also may contain copyrighted materials as noted in the text. Permission to reproduce copyrighted items must be secured from the copyright owner.

Suggested citation:

Helweg, D.A., Keener, V., and Burgett, J.M., 2016, Report from the workshop on climate downscaling and its application in high Hawaiian Islands, September 16-17, 2015: U.S. Geological Survey Open-File Report 2016-1102, 25 p., http://dx.doi.org/10.3133/ofr20161102.

ISSN 2331-1258 (online) 


\section{Preface}

Over the last 5 years, various professionals have been attempting to identify the best actions to prepare for changing climate in the subtropical and tropical Pacific. In the subtropical and tropical Pacific, changing climate is projected to influence precipitation, freshwater availability, coastal conditions, and other environmental variables that are of great significance to resource managers. The resources managed have high local, regional, and global significance, and include critical drinking water sources, ecosystems related to cultural survival, and endangered species.

Research suggests some subregions, and biomes within subregions, are likely to experience significant changes in precipitation input, recharge, and other environmental factors. These changes will not necessarily be uniform on the island or island chain scale. In the light of a changing climate, resource managers and decision makers in Hawai'i and the United States Affiliated Pacific Islands (USAPI) need good projections of precipitation, freshwater recharge, and other climate variables at the 10-, 20-, and 100 -year time intervals. They also need the uncertainty in those predictions understood and expressed in ways that allow it to be included in management decisions.

However, currently available projections derived from two different approaches to climate model downscaling (dynamical downscaling [DD] and statistical downscaling [SD]) produce dissimilar results for rainfall for some times and locations. Because of disparities in projections, natural resource managers and decision makers have low confidence in using this information and thus are unwilling or unable to include climaterelated projections in their decisions.

The Pacific region is fortunate to have, in addition to climate modelers and managers, three organizations dedicated to the development of communication strategies and tools for climate change action. The Department of the Interior (DOI) Pacific Islands Climate Science Center (PICSC), the Pacific Regional Integrated Sciences and Assessments (Pacific RISA) program, and the Pacific Islands Climate Change Cooperative (PICCC) work on different aspects of these issues and collaborate and communicate regularly to identify critical informational, communication, and other needs.

Staff with the PICSC, the Pacific RISA, and the PICCC began discussions in 2014 regarding holding a workshop to address the challenges arising from current modeling approaches. The general proposal was to bring together the two modeling teams, plus key model users and water resource managers, to compare the two approaches and engage in a discussion of how to provide climate knowledge and predictions usable by resource managers.

In the development of the workshop, the complexity of the scientific and other issues led to a narrowed focus on the high Hawaiian Islands. The significance of needing better information from and communications with climate modelers across the tropical and subtropical Pacific is unquestioned. However, the workshop conveners determined the 
best path to develop shared understandings and strategies would come from an initial focus on a region where more modeling and management infrastructure is in place.

The workshop conveners believe that this workshop identified critical communication and informational needs for Hawai'i and the U.S. Affiliated Pacific Islands (USAPI). This report outlines the methods and outcomes of the workshop so that stakeholders in this area, and people engaged with similar efforts in other regions may continue to engage with this issue. The conveners hope and intend that these issues will continue to be addressed in different forums across Hawai'i and the USAPI. 


\section{Acknowledgments}

Pre-workshop assessment research was supported by the Pacific Regional Integrated Sciences and Assessments (RISA) program under NOAA Award NA10OAR4310216. The DOI Pacific Islands Climate Science Center provided invitational travel support to several workshop participants. Thanks also to the staff of the Hawai'i Imin International Conference Center of the East-West Center who provided an excellent facility and logistical support for this workshop. Superb services for workshop facilitation, logistics, and report production were provided by Jonathan Likeke Scheuer and Bianca Isaki under U.S. Geological Survey Award No. G15PX00867 from the Department of the Interior Pacific Islands Climate Science Center. 


\section{Contents}

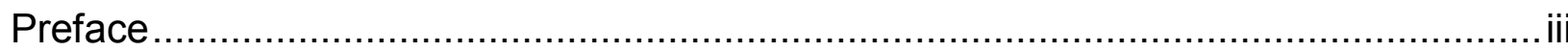

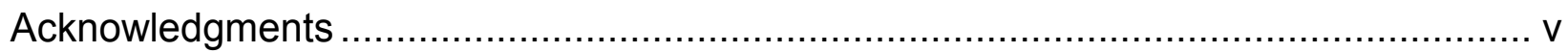

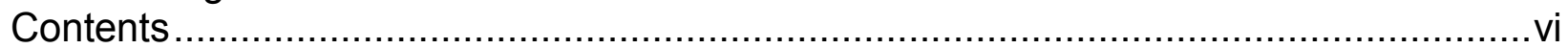

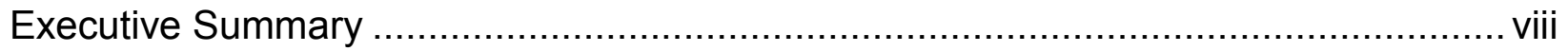

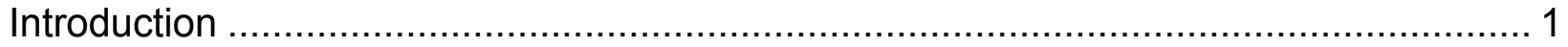

Pre-Workshop Survey: Perceptions of Climate Needs and Downscaling Data by

Modelers and Resource Managers in Hawai'i ........................................................ 5

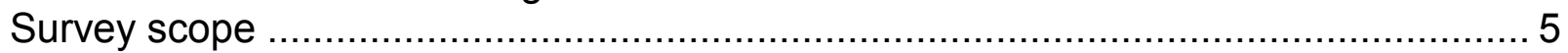

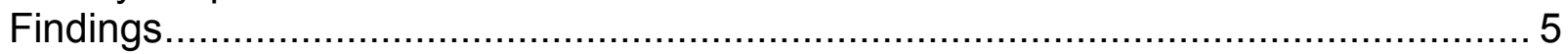

Climate Scientist Survey Responses....................................................... 5

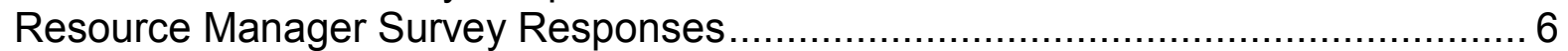

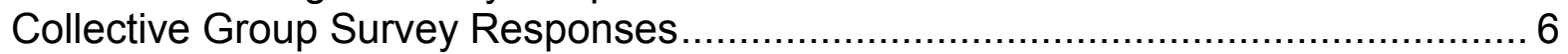

Survey Inquiries into Workshop Goals ...................................................... 7

Workshop Participant Responses to the Pacific RISA Survey …............................ 7

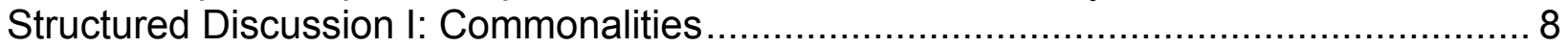

Search for Commonalities between Downscaling Models ...................................... 9

Limits of SD and DD Downscaling Models ........................................................ 9

Synchronizing Delivery of Climate Information to Resource Mangers....................... 10

Consultation between Managers and Climate Modelers Going Forward ................... 12

Structured Discussion II: Best Science Practices, I.............................................. 13

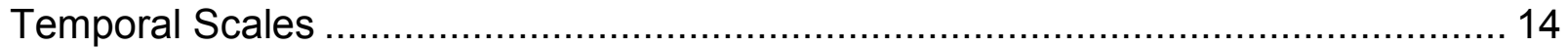

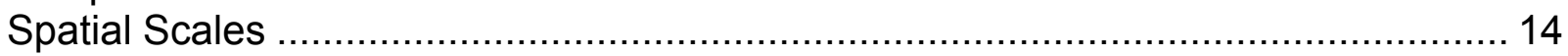

Structured Discussion III: Applications of Current Products ..................................... 15

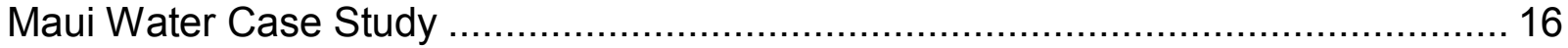

Responses from Resource Managers ........................................................ 16

Collaborative Transformation Paradigm of Climate Model Data Applications ............ 17

"Loading Dock," "Concierge," and Other Data Dissemination Methods...................... 17

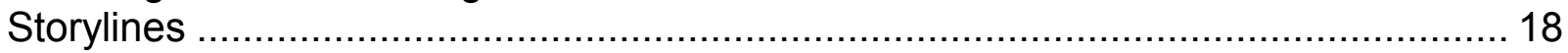

Structured Discussion IV: Best Science Practices, II.............................................. 18

Participant Agreements .......................................................................... 19

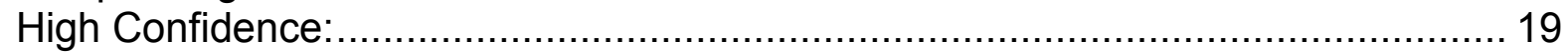

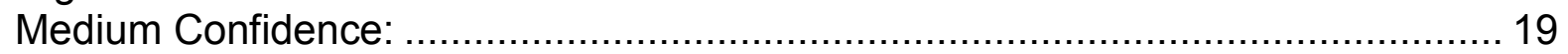

Detailed Discussion of Confidence Agreements ................................................... 19

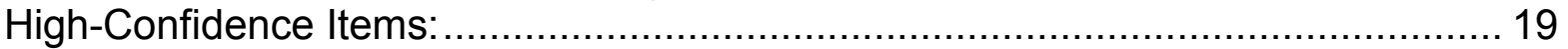

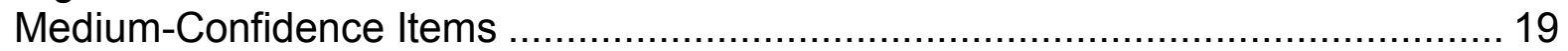

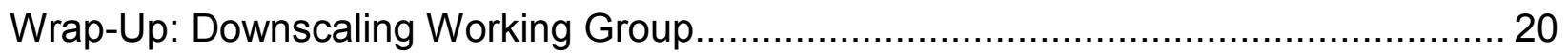

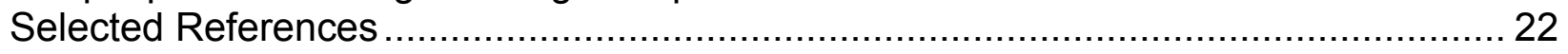

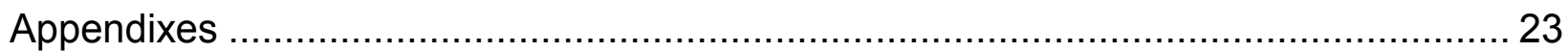

Appendix 1. "Review of RISA Survey: Insights Learned Through Using Downscaled Climate Products" by Victoria Keener.................................................................. 23

Appendix 2. "Island Downscaling Resources Matrix" model descriptions.................... 23 
Appendix 3. "Presentation on Statistical Downscaling" by Oliver Elison Timm........... 23

Appendix 4. "Dynamical Downscaling" by Yuqing Wang ........................................ 23

Appendix 5. "The Climate Change Conundrum: A Water Resource Management

Perspective" by Lenore Ohye ....................................................................... 23

Appendix 6. "Estimating Climate-Change Impacts on Groundwater Recharge for the Island of Maui, Hawai'i" by Alan Mair

Appendix 7. "Drought and Fire in Hawai'i and the US Affiliated Pacific Islands" by Christian Giardina and Michelle Mansker....

Appendix 8. "Application Perspective Case Studies-Hawaiian Species and Habitat Conservation in a shifting climate" by Lucas Fortini, Sierra McDaniel, Rick Camp, and Jim Jacobi

\section{Figures}

1. Photograph of climate downscaling workshop attendees

4

2. Diagram showing "adaptive management" of communication between climate modelers and users 


\section{Executive Summary}

The "Workshop on Climate Downscaling and its Application in the High Hawaiian Islands" was held September 16-17, 2015 at the East-West Center in Honolulu, Hawai'i. Approximately 30 people participated in the workshop, including scientists from laboratories representing different theories of climate model downscaling, impactmodelers, intermediary scientists (whose work is intermediate between climate projection and direct application, performing important transformational and translational steps), and natural resource managers and other end users,. During the closing plenary session, participants developed consensus statements concerning aspects of future climate projections in which they placed high or medium confidence. Significantly, participants found few areas of agreement, and there was much disagreement remaining at the close of the workshop. Participants' substantial difficulty in finding points of agreement underscored an already widespread perception that more work is needed.

In addition to the areas of high and medium confidence items identified during the final session, workshop presentations and discussions produced significant outcomes and findings as follows:

1. The Pacific RISA survey found climate scientists generally reported statistical downscaling (SD) and dynamical downscaling (DD) did "adequate" to "well" in reproducing historical average annual temperature and precipitation and in projecting future climate variables. In marked contrast, all groups of resource managers (freshwater, wildfire, and ecosystems managers) concurred in not knowing whether one downscaling method was better.

2. In response to Pacific RISA survey inquiries into the use of different transformed information at different timescales, resource managers reported a lack of familiarity with, or use for, El Niño Southern Oscillation (ENSO) signals, yet also reported that a "seasonal" frequency of observations for other conditions would be useful. This discrepancy could be attributed to a lack of familiarity with the ENSO acronym for the EI Niño Southern Oscillation, or lack of familiarity with the association between ENSO and seasonality in the Pacific Islands.

3. Freshwater and ecosystem managers especially sought to learn the status of downscaled data products, information on uncertainty, and means of accessing climate modeling output. More than half of the wildfire managers hoped to gain information on how to access climate modeling data from the workshop. This response reinforces the potential value of a Climate Downscaling Working Group.

4. Overall, the Pacific RISA survey strongly highlighted a need for better communication between climate scientists as knowledge developers, and a broader audience of those implementing programs based on scientific results.

5. During the "Commonalities" structured discussion, one participant proposed identification of specific metrics (for example, spatial, temporal, and so on) that were important for each community and suggested that such metrics should be formed by considering which measures are important for different communities; 
6. Also during the "Commonalities" discussion, one participant proposed distinguishing between points of "agreement" and agreement as to what is considered "predictable", and then to further elaborate what aspects of future climates are predictable.

7. Participants noted that the breadth of uncertainty in climate projections could indicate a need to prepare for a wider variety of climate conditions and suggested adapting management decisions to a range of scenarios based on storylines or plausible trajectories; modeling of these scenarios has produced equivocal results on changes in the proportion of time in El Niño, La Niña, and neutral conditions (ENSO symmetry).

8. SD and DD downscaling models are both limited by the availability of local data. Thus, some modelers believed both models' capacity to project climate future in Hawai'i should be contextualized by these limits.

9. Resource managers found information on uncertainty was useful for establishing a conservative precautionary perspective for their management efforts. Consistent with number 7 above, participants noted that the breadth of uncertainty in climate projections could indicate a need to prepare for a wider variety of climate conditions.

10. Participants also challenged assumptions that the source of uncertainties and the source of differences in model outputs were necessarily linked; examination of the source of uncertainties may produce more meaningful information and such an examination may not require standardization of methods.

11. In regards to DD models, inquiry into the best scaled-resolution may require identifying the asymptote at which higher resolution would not provide different model outputs in the absence of regional or local information. Resource managers may be able to assist in refining this identification by communicating decision-making needs that could be integrated into research parameters, including the level of resolution and grid sizes.

12. Better elaboration of the critical work in the intermediate space between climate scientists and resource managers was suggested, as well as recognition of the need for resources for such transformation and translation work. The "iterative process" model similarly underscored the importance of supporting intermediary and translation work on downscaling outputs.

13. Several proposed co-production of modeling, in which users approach modelers with a problem and modelers explain what answers climate data could provide.

14. More environmental monitoring is needed to produce more climate data. This is particularly important because existing monitoring sites do not cover the geographic and temporal extent required to adequately represent current climate. This representation is necessary to understand the relationships between larger scale atmospheric features and fine scale meteorological variables for SD; it is also necessary to understand the strengths and deficiencies in DD, and thus to know when and where DD output may be reliable. 



\title{
Report from the Workshop on Climate Downscaling and its Application in High Hawaiian Islands, September 16-17, 2015
}

\author{
By David A. Helweg, ${ }^{1,2}$ Victoria Keener, ${ }^{3}$ and Jeff M. Burgett ${ }^{4,5}$
}

\section{Introduction}

Despite the importance of knowing how climate change in the next century will manifest at landscape scales of the high Hawaiian islands (Hawai'i Island, Maui Nui, O'ahu, and Kaua'i), there remains significant disparities in the assumptions and products between different schools of climate downscaling, as well as varying levels of debate among modelers of future climate conditions, who we describe as "intermediary scientists and modelers" who work to translate climate change model information for resource managers, and the resource managers themselves. The need to address these issues was the catalyst for a range of discussions in the "Workshop on Climate Downscaling and its Application in the High Hawaiian Islands" (herein, the workshop) held September 16-17, 2015 at the East-West Center in Honolulu, Hawai'i. Approximately 30 people participated in the workshop, including scientists from laboratories representing different theories of climate model downscaling, impact-modelers, transformers of model results who work both with resource managers and modelers to facilitate co-development of useable products (henceforth "knowledge transformers"), and natural resource managers and other end users.

In the subtropical and tropical Pacific, anthropogenic climate changes are predicted to influence freshwater resources, weather events, air temperature trends, and frequency and intensity of storms and droughts, among other environmental variables, by the end of the $21 \mathrm{st}$ century. Two approaches dominate climate science downscaling: physics-based ("dynamical") and statistics-based downscaling methods. These models are producing a range of dissimilar predictions for some locations, timeframes, and parameters. Natural resource managers and decision makers have raised questions about how to understand model projections and how to integrate climate-related projections in their resource management decisions. The U.S. Department of the Interior Pacific Islands Climate Science Center (PICSC) and its partners, the Pacific Islands Climate Change Cooperative (PICCC) and the National Oceanographic and Atmospheric Administration (NOAA) Pacific Regional Integrated Sciences Assessment (Pacific

\footnotetext{
${ }^{1}$ U.S. Department of the Interior Pacific Islands Climate Science Center

${ }^{2}$ U.S. Geological Survey

${ }^{3}$ East-West Center, Pacific Regional Integrated Sciences and Assessments Program

${ }^{4}$ Pacific Islands Climate Change Cooperative

${ }^{5}$ U.S. Fish and Wildlife Service
} 
RISA) have prioritized development of downscaled climate modeling products appropriate for island scales.

The purpose of this workshop was to conduct an evaluation of available downscaled climate model products for Hawai' $i$ and to initiate a climate downscaling application strategy for the Hawaiian Islands. The first day of the workshop was organized around a focus on technical climate modeling issues and the second day focused on resource manager applications and needs. Workshop goals and objectives consisted of (1) reviewing a Pacific RISA survey on perceptions of downscaled climate products from modeler and end-user perspectives; (2) identifying agreements among current projections in the main Hawaiian Islands; (3) developing best applications of current products (from a management perspective) in terms of locations, spatial scales, and temporal frames; (4) developing best practices for climate downscaling (from a science-researcher perspective) that are envisioned as a framework for modeling conditions that will facilitate comparison of results and outputs; and (5) providing opportunities to bring other approaches into the discussion.

The workshop included four structured discussions, as well as formal presentations by climate scientists working on statistical downscaling (SD) and dynamical downscaling (DD) modeling, resource managers concerned with climate change impacts on freshwater resources, the threat of wildfire, and ecosystem health and sustainability, and a Pacific RISA researcher who conducted a pre-workshop survey of identified stakeholders and participants. Structured discussions provided forums for deliberations over the practical provision of climate change data to resource managers and planners.

The first discussion, entitled "Commonalities," was held after presentations by an SD modeler and a DD modeler, each of whom presented their approaches to Hawaiian Islands climate projections. Model descriptions are appended to this report in Appendix 2. "Commonalities" was directed towards identification of best practices for applying different climate models, the ways these models have been used by resource managers, and best science research and products for communicating modeling application information between modelers and managers.

The second structured discussion ending the first day of the workshop, "Best Science Practices, Part I," queried climate modelers about ideal questions to ask in developing best practices for climate downscaling. The second day began with freshwater, wildfire, and ecosystem resource managers presenting perspectives on need-based applications of climate modeling data and illustrated these needs in case studies from their work. This was followed by the third structured discussion, "Application of Current Products," which sought to engage participants in addressing needs and issues raised in and through the resource manager presentations. Finally, the "Best Science Practices, Part II" structured discussion concerned identification of agreements among current climate projections for the main Hawaiian Islands. At the close of the workshop, climate modeling researchers and others interested in furthering these discussions agreed on the need to create a regional Climate Model Downscaling Working Group.

As detailed in this report, the first workshop objective (review of the Pacific RISA survey) provided a highly valuable framework for discussing gaps between climate researchers and resource managers in their perspectives on climate modeling issues. The second objective of identifying agreements among current projections resolved into a discussion of relative "confidences" in various projections for climate variables for the main Hawaiian Islands. Consensus on this issue was a significant workshop outcome. The third objective of developing Best Applications of current products for managers was likewise adjusted during the course of 
the workshop to better account for challenges managers faced in applying current products for various resource management decisions. For example, participants discussed management actions requiring immediate decision-making, for which otherwise relevant climate projections would have no feasible near term uses. In such situations, participants discussed integrating other kinds of data into their decision-making process. The fourth objective of developing Best Practices for climate downscaling from a science-researcher perspective was critiqued and reframed by participants' critical engagement with the concept of "comparison" and the scale at which a Hawai' $i$ - or Pacific region-focused climate modeling comparative project could produce useful results. Finally, the workshop met the fifth objective of providing opportunities to bring other approaches into the discussion in at least two ways. Participants variously described situations in which they had adapted downscaling instruments and outputs to coordinate with different kinds of inputs in order to address management and research questions. Additionally, participants' broad familiarity with approaches taken to comparable questions about climate model downscaling in other regions opened discussions about the scope of, and opportunities for, collaborative efforts concerning Hawai'i. Importantly, workshop participants described "teachable moments" that occurred through their efforts to work with disparate downscaling products. Teachable moments often led to participants questioning assumptions provided by the workshop framework, such as the presumption that "standardizing" model variables and outputs would result in comparable outputs, or that the generated information would be meaningful or actionable for end users. Such teachable moments constitute a valuable outcome of the workshop and are partly compiled in the "Summary" section of this report.

This Open-File Report highlights themes and findings from the Pacific RISA survey and the workshop's four structured discussions titled (1) Commonalities, (2) Best Science Practices I, (3) Application of Current Products, and (4) Best Science Practices II. Some formal presentation content has been included as appendixes, including presentations by the following people: Victoria Keener, Pacific RISA, "Review of RISA Survey: Insights Learned Through Using Downscaled Climate Products;" Oliver Elison Timm, University at Albany-SUNY, "Presentation on Statistical Downscaling"; Yuqing Wang, University of Hawai'i at Mānoa, "Dynamical Downscaling"; Lenore Ohye, State of Hawai'i Commission on Water Resource Management, "The Climate Change Conundrum: A Water Resource Management Perspective"; Alan Mair, U.S. Geological Survey (USGS), "Estimating Climate-Change Impacts on Groundwater Recharge for the Island of Maui, Hawai 'i”; and Christian Giardina, U.S. Department of Agriculture Forest Service and Michelle Mansker, U.S. Army, "Drought and Fire in Hawaii and the US Affiliated Pacific Islands.” Lucas Fortini, Sierra McDaniel, Rick Camp, and Jim Jacobi's presentation "Application Perspective Case Studies-Hawaiian Species and Habitat Conservation in a shifting climate" is appended in revised form. 


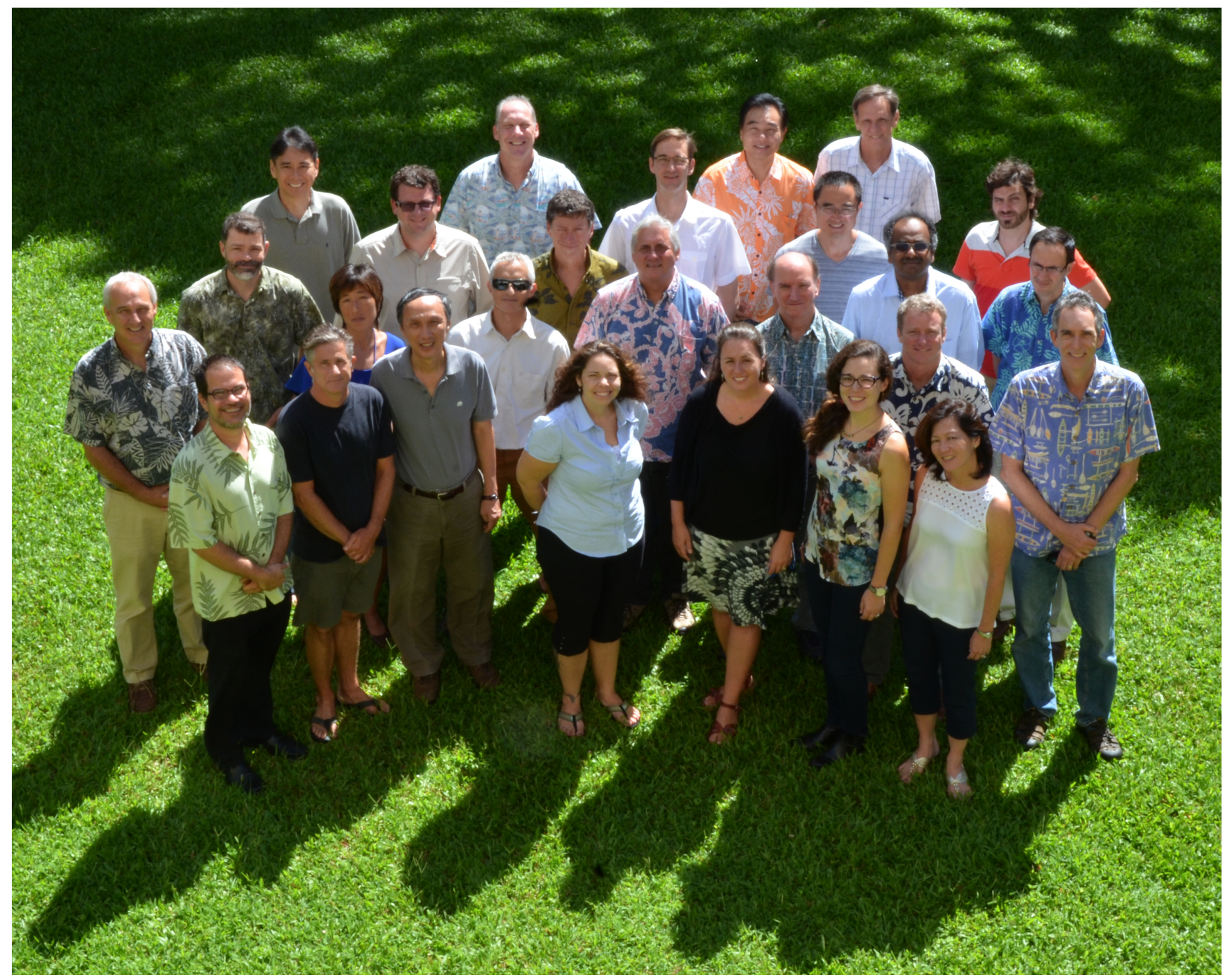

Figure 1. Photograph of climate downscaling workshop attendees. Attendees from left to right (back row) Delwyn Oki, U.S. Geological Survey (USGS) Pacific Islands Water Science Center (PIWSC); Dave Helweg, Department of the Interior Pacific Islands Climate Science Center (PICSC); Ethan Gutmann, U.S. National Center for Atmospheric Research (NCAR); Yuqing Wang, University of Hawa'i at Mānoa (UHM) International Pacific Research Center (IPRC); Tom Giambelluca, UHM Department of Geography; Lucas Fortini, Pacific Islands Climate Change Cooperative (PICCC) and USGS Pacific Island Ecosystems Research Center (PIERC); (middle row) Steve Anthony, USGS PIWSC; Jeremy Littell, Alaska Climate Science Center (AK CSC); Bianca Isaki, workshop assistant; Martyn Clark, NCAR; Rick Camp, University of Hawai'i at Hilo; Gordon Tribble, USGS PIERC; Chunxi Zhang, UHM IPRC; $\mathrm{H}$. Annamalai, UHM IPRC; Oliver Elison Timm, University at Albany-SUNY; (front row) Jonathan Likeke Scheuer, workshop facilitator; John Marra, NOAA National Environmental Satellite, Data, and Information Service (NESDIS); Pao-Shin Chu, UHM IPRC; Christian Giardina, U.S. Department of Agriculture Forest Service; Michelle Mansker, U.S. Army; Sierra McDaniel, U.S. National Park Service Hawai'i Volcanoes National Park; Jim Jacobi, USGS PIERC; Victoria Keener, East-West Center Pacific 
Regional Integrated Sciences and Assessments (RISA); Alan Mair, USGS PIWSC; Lenore Ohye, State of Hawai'i Commission on Water Resources Management (CWRM); Jeff M. Burgett, PICCC; (not pictured) Barry Usagawa, City and County of Honolulu Board of Water Supply. Photograph by Shayne Hasegawa, East-West Center External Affairs.

\section{Pre-Workshop Survey: Perceptions of Climate Needs and Downscaling Data by Modelers and Resource Managers in Hawai'i}

Victoria Keener, principal investigator of the Pacific RISA, conducted a pre-workshop survey, the results of which were analyzed for her workshop presentation (Appendix 1). The preworkshop survey sought to compile information needs of resource managers from climate scientists and to gauge each groups' perceptions of each other. This presentation of Pacific RISA Survey results helped to frame the purpose of the workshop and needed discussions.

\section{Survey scope}

Pacific RISA surveyed 19 climate scientists and three groups of natural resource managers that specifically work in Hawai'i: 12 wildfire managers, 19 ecosystem managers, and 15 freshwater managers. The purposes of the survey study were (1) to frame the workshop discussions; (2) to offer insight into different groups' needs and perceptions; (3) to produce background information on the kind of climate information different resource managers use and need; and (4) to identify differences between the groups. On average, the 65 survey participants had between 20 and 30 years of experience; the climate scientists were primarily academics; and managers were mostly in county, State, or Federal agencies. Because sample sizes were small, statistical significances of differences among survey groups were not assessed.

\section{Findings}

The survey asked resource managers and climate scientists to gauge their familiarity with each others' areas of expertise and both groups reported limited understanding. Most climate scientists had either some familiarity ( 38.5 percent) or a general familiarity ( 30.8 percent) with natural resource policy and planning processes. Sixty percent of resource managers had "some familiarity" with modeling climate systems in Hawai'i or held a nontechnical familiarity with models and outputs. Pacific RISA also submitted separate survey questions to these groups.

\section{Climate Scientist Survey Responses}

Climate scientists reported spending the majority of their time on basic research questions, and generally thought that more data was needed to evaluate the accuracy of many currently projected climate variables. Climate scientists were asked to gauge (1) the ratio of activities devoted to operational and basic research purposes; (2) their levels of confidence in modeled projections of average changes in climate variables including seasonal and annual temperatures, sea level rise (SLR), seasonal and annual precipitation, and frequencies of flood, drought, and storms; (3) if the kind of information from resource managers and other end users of climate modeling data would help climate scientists; and (4) their understanding of the kinds of climate data useful to resource managers. Climate scientists reported spending less than half 
of their time on operational research. Researchers were most confident with projections of average annual temperature, SLR, and seasonal temperature, and were less confident about annual and seasonal precipitation and the frequency of floods, droughts, and storms. A majority of climate scientists reported that their work would benefit from improved knowledge of policy and (or) management perspectives on the most important or sensitive part of a particular issue (76.9 percent); and better end-user understanding of the limitations and strengths of climate models (69.2 percent). Keener noted a written-in "other" response stating that knowledge of "what decision, at what time frame" from end users would be specifically helpful. Climate scientists believed resource managers would be most interested in the frequency and intensity of extreme events.

\section{Resource Manager Survey Responses}

Resource managers had varying levels of familiarity with downscaled climate models and projections, but confirmed that more information about data uncertainty was needed for them to rely on projections for management decisions. Resource managers, disaggregated by managed resource category (ecosystems, wildfire, and freshwater resources), were surveyed separately from climate scientists regarding their familiarity with, and use of, climate change projections. While most ecosystem managers (33.3 percent) and wildfire managers (41.7 percent) assessed themselves as having "no familiarity" with the use of climate projections, the bulk of the freshwater managers reported using projections regularly (41.7 percent). Resource managers generally shared a primary concern with obtaining more information on degrees of uncertainties across various climate change projection data. They were less interested in information on the technical details of climate models. They sought more information on how different downscaling outputs for particular scenarios and time horizons could be applied, as well as the limitations of those outputs. Specific written responses included requests for better communication and training on what can and cannot be provided through climate modeling projections.

Resource manager responses to inquiries into their understandings of levels of certainty for climate variables, even when disaggregated by resource category, placed annual SLR and average air temperature as "most certain" and average annual evapotranspiration and precipitation in the next 75-100 years as the "least certain." Managers were also queried regarding the temporal and spatial scales that would be most useful for their work. Managers generally considered the "watershed" scale the most crucial, and broader spatial scales (statewide and Pacific Island regional) the least crucial. In response to inquiries into what frequencies of observations of current conditions would be helpful to guiding decision making, resource managers reported a lack of familiarity with ENSO (El Niño Southern Oscillation) signals, yet also reported that a "seasonal" frequency of observations for other conditions would be useful. This discrepancy could be attributed to a lack of familiarity with the ENSO acronym.

\section{Collective Group Survey Responses}

All groups believed scientific expertise should be prioritized over other considerations such as the interests of industry or commerce, public opinion, and political opinions in making climate change policies. When asked to rate the adequacy of data and resources for Hawai' $i$, across all groups, the dominant response was that data availability for climate change analysis and management was "somewhat adequate." All of those surveyed, but especially climate scientists, believed financial support for basic climate research was either "very" or "somewhat" inadequate. Most resource managers, especially wildfire managers, believed financial support for 
application of climate research in resource management was very inadequate. Ecosystem managers were most likely to believe climate adaptation efforts in Hawai' $i$ were very inadequate (93.3 percent). Finally, participants were asked how important various aspects of climate model research were to them, personally. Technically correct results, advancing the basic understanding of regional climate systems, and publication in high-impact academic journals, were more important to climate scientists than manager groups. All groups, including climate scientists, believed the following to be important: climate research being useful to policy makers and resource managers, helping communities and ecosystems adapt to climate change, and producing information that is understandable to decision makers.

The majority of all groups also believed climate scientists should be "very involved, from project conception to final data delivery" in providing projections to end users and resource managers. Written responses specified "cooperative approaches" to appropriately use individual strengths and compensate for weaknesses and suggested filtering information through an "intermediary," although direct dialogue must also happen.

\section{Survey Inquiries into Workshop Goals}

The Pacific RISA survey included inquiries tailored to the goals of the workshop, which included investigation into tolerances for different climate models and the particular interests of workshop participants. Most climate scientists reported wanting to engage with each other to understand differences and to better communicate results to resource managers. Climate scientists generally wanted to learn what others were working on and get updates on downscaled data products and few reported seeking to create a "streamlined regional modeling framework." Resource managers overall reported differences in their interests in participating in the workshop. Freshwater and ecosystem managers especially sought to learn the status of downscaled data products, information on uncertainty, and also information on how to access climate modeling data. More than half of the wildfire managers hoped to gain information on how to access climate modeling data from the workshop. Overall, the most surprising findings of the Pacific RISA survey were participants' report of their eagerness to collaborate, and differences between freshwater resource managers and other resource managers, in that freshwater managers have a higher familiarity with use of climate projections.

\section{Workshop Participant Responses to the Pacific RISA Survey}

Workshop participants greatly appreciated the Pacific RISA survey's assessments of existing perceptions, concerns, and interests, particularly as they framed workshop purposes. Participants underscored the usefulness of the Pacific RISA survey results in supporting agencies that fund climate science research and in ascertaining how climate scientists can produce data that, when translated, may be actionable for managers. Keener noted the singularity of Hawai' $i$ and Pacific regional scientists and resource managers' extensive and increasing awareness of climate change. A limited survey of Hawai'i managers' belief as to whether climate scientists agreed climate change was happening increased from 70 percent in 2012 to 90 percent in 2015. The U.S. national level of such belief is about 45 percent (Leiserowitz and others, 2015). One participant felt that Pacific Islanders want to learn about more solutions to climate change and they do not need to be convinced that it is happening.

As would be repeated throughout the workshop, the communication of uncertainty between climate scientists and resource managers was identified as a crucial issue. One observed that scientists and managers ask different questions about uncertainty. Scientists ask; why is 
something uncertain? Managers ask; how uncertain is it? Participants also commented on specific assumptions and limitations of the Pacific RISA survey instrument and its scope of inquiry. These comments included the following points: (1) there is an absence of impact modelers and knowledge transformers in the surveyed population; (2) recognition that board and commission members, rather than resource managers, are sometimes the decision makers who are integrating climate modeling data, which adds another layer of communication complexity; (3) not all climate scientists identify as climate modelers; and (4) agricultural managers could be specifically surveyed. Workshop participants included scientists who produced models tailored to resource manager and other end-user needs by "translating" SD and DD climate modeling outputs. These impact modelers and knowledge transformers recommended conducting a second survey inclusive of, and disaggregated for, responses from knowledge transformers in order to better convey issues arising between climate scientists, modelers and the end users. These limits and assumptions will be addressed in development of a future refinement of this Pacific RISA survey project. Pacific RISA additionally produced a table of Hawai'i climate downscaling products. Both this resource document and RISA survey results were distributed to workshop participants (see Appendix 2).

\section{Structured Discussion I: Commonalities}

The first structured discussion, titled "Commonalities," followed presentations from statistical and dynamical climate downscaling modelers. Oliver Elison Timm from the Department of Atmospheric and Environmental Sciences, University at Albany-SUNY, gave a presentation on his research on SD of precipitation in Hawai'i (see Appendix 3). Yuqing Wang from the International Pacific Research Center and Department of Atmospheric Sciences, University of Hawai'i at Mānoa, presented his work on DD across the Pacific region (see Appendix 4). These two efforts provide the only downscaled climate projections to date for Hawai' $i$. The "Commonalities" discussion sought to provide climate downscaling modelers a venue for identifying areas of confidence for both SD and DD projections for the main Hawaiian Islands. These identified areas of confidence, it was proposed, might aid in further formulation of best practices for applying different models. Participants challenged this proposal on multiple grounds.

Victoria Keener introduced the Commonalities discussion by presenting survey responses to inquiries into the capacities of SD and DD models of Hawai' $i$ to reproduce historical average annual temperature and precipitation and reproduce temperature develop different climate projections. Fewer than 20 participants from each group (climate scientists and freshwater, wildfire, and ecosystems resource managers) provided responses. Climate scientists' results were varied, but they generally reported that SD and DD did "adequate" to "well" in these kinds of climate projections. In marked contrast, all groups of resource managers (freshwater, wildfire, and ecosystems managers) concurred that they did not know whether one downscaling method was better, although they were interested in learning more. A key comment was that resource managers were not the appropriate group to rank the relative reliability of these downscaling methods because they generally look to impact models, as opposed to climate models.

At the conclusion of the second Pacific RISA survey presentation, some resource manager participants commented that the previous climate downscaling modeling presentations were too technical and recommended taking a different approach to presenting this information. These comments brought attention to a more general tension arising from two discussion threads that developed within the workshop, the first between different climate modelers, and the second 
between climate modelers and resource managers. On the one hand, climate model developers discussed technical and particularized differences between their models and model outputs. On the other hand, resource managers and end users sought to discern applications of different climate models. Participants further noted certain climate model outputs may be irrelevant to certain short term management issues because non-climate factors would be more determinative for decision-making purposes. This issue of disparate timeframes between management decision making and modeled projection outputs emerged in many workshop discussions.

\section{Search for Commonalities between Downscaling Models}

Commonalities between downscaling models were elusive, in part because the workshop structured this discussion around inquiry into a comparative framework. Participants suggested that SD and DD models are not competing, but rather they may exist on a continuum of approaches to the same problem. The attempt to draw conclusions based on comparison between downscaling-model outputs was highly scrutinized and met with many challenges. For instance, both SD and DD models may tell us that precipitation at a certain time in the future will be "x," but an agreement on " $x$ " between the two models, some pointed out, would not directly translate to a higher level of confidence in this output. Participants cautioned that similar outputs from both models could be equally wrong in the sense of almost certainly being inexact. Moreover, two models could yield highly similar outputs, but again they would very likely be inexact. In other words, quantitative agreement among models does not imply certainty about the future climate. A broader question raised by participants concerned whether such comparisons could be meaningful and how one would determine the meaning of that comparison. Sharing conclusions in common, some suggested, may not indicate a basis for increased confidence in the conclusion because methodologies used by each downscaling model for quantifying uncertainty were different. To find commonalities, one participant proposed that we should identify which metrics (for example spatial or temporal) are important. Additionally, those metrics should be formed by considering which measures are important for different communities holding interests in climate modeling and downscaled outputs. This would be part of a larger conversation of understanding how uncertainties matter to different communities. One proposal suggested using a controlled, systematic approach to characterize inter-model differences and uncertainties.

\section{Limits of SD and DD Downscaling Models}

According to Timm and Wang, SD and DD models' relative capacities differed. DD methods allow inclusion of historical mean changes associated with the Pacific Decadal Oscillation (PDO) and ENSO. Both SD and DD modelers did not believe that their models could capture the future variability associated with those changes. Modelers identified this as a common limitation for both the SD and DD models used here. Both rely on global climate models (GCMs) and data concerning observed inter-annual variability. GCMs, presenters stated, do not simulate PDO or ENSO variability well.

Failing to account for that variability, according to modelers, could be significant because it may likewise fail to account for changes in symmetry of the ENSO cycle, such that ENSO may change in terms of domination by El Niño or La Niña. Yet, they also cautioned that modeling of these scenarios has produced equivocal results on ENSO symmetry changes. The SD and DD models, the presenters continued, are both also limited by the availability of local data. Thus, some modelers believed both models' capacity to project climate futures in Hawai' $i$ should be contextualized by limits imposed by lack of data and modeling complexity. 
Participants noted that at a certain point in increasing downscaling resolution, impacts are more likely to be dominated by local, non-climatic factors. For example, as downscaling increases from about $1 \mathrm{~km}$ down into the realm of tens or hundreds of meters, factors such as soil ecohydrology and specific vegetation characteristics will begin to become more salient than climate and weather conditions. This is a challenge because applications of climate projections to natural resource management and conservation questions often request the highest possible spatial resolution. In such cases, if a downscaling model lacks observational data at a high resolution, then highly resolved outputs would not be meaningful. Several participants believed this limit may be determinative for management decisions that operate on spatial scales requiring such local inputs. Participants discussed the possibility of using detailed information on topography (for example, slope, aspect, or elevation) to downscale meteorological fields from regional climate model projections to the very fine spatial scales needed for ecological modeling (Newman and others, 2014; Thornton and others, 1997; Dubayah and Rich, 1995).

Participants inquired into SD and DD utilization of historical trend data. Historical trends were generally interpreted to show a statistically significant change in climate indicators, yet SD and DD models differed in whether their outputs were consistent with some of these observed trends. Modelers responding to inquiries into whether their future projections were consistent with documented trends raised further considerations, including the following items:

- Assessing consistency of climate "hindcasts" for recent decades with measured environmental conditions (for example, rainfall) would require calibration between the spatial and temporal pattern of measurements and the spatial and temporal scale of the downscaling models.

- Contributions to observed hydrologic changes caused by climate versus other factors (for example, water diversion, or land cover change) in the latest 30-year or 100-year historical trends would need to be disaggregated.

\section{Synchronizing Delivery of Climate Information to Resource Mangers}

Resource managers felt they lacked climate projections in actionable form. This lack can result in various consequences:

- Despite ongoing debates at the workshop about perception of reliability of climate projections, the reality is that resource management decisions are being made on existing and (or) potentially obsolete data.

- In some cases, those decisions are made on the basis of partial understandings or partial representations of particular climate change projections. One example of such a use was that existing decision-making was based on the non-conservative projections of the DD model that more groundwater would be available on one of the Hawaiian Islands.

- Decision-making, some observed, will occur even in the absence of consensus on the best available information. Put otherwise, modeling information may not be meaningful to management decision-making timeframes or communicated in a way that accurately conveys its meaning. In such cases, modeling information may not be used or may be used inappropriately.

- Even with projections otherwise deemed reliable, resource managers may need information about timeframes for which downscaling methods have little skill. In light of the potential uses of unexplained and inconsistent results under SD and DD models, some attendees proposed a process for managing the release of climate modeling results that would deliberately build transformation and translation into the release. As would be 
described in a subsequent discussion, climate modelers have also utilized a "loading dock" practice in which bare data has been made available without guidance on the kinds of meanings that could be drawn from that information.

Several approaches to the process of delivering climate research information to resource managers were discussed. First, the approach upon which the workshop was partly premised, climate scientists could produce guidance on their most confident climate projections and how and where they may be used. This guidance could be as minimal as indicating the direction of change for particular climate variables.

In the second approach, resource managers were asked to specify the amount of certainty or the kind of information needed to constitute "actionable" scientific information. Resource managers responded that the kind of actionable information needed depended on the kind of management action taken. Several resource managers believed a consensus among modelers about ranges of predictions for climate conditions, signs, and guidance on using downscaled outputs would be useful to such decision making.

- Wildfire managers offered that different resources, such as specific threatened and endangered species, required different levels of certainty and scales of information. A higher level of certainty would be required to initiate relocation of discrete populations of endangered species than to calibrate fire suppression model projections.

- Freshwater managers also described different management approaches to increasing resiliency as opposed to near-term policy decisions. Trends and a general sense of whether a signal is positive or negative could guide resiliency, including small steps toward longer term planning. Quantitative data provided in the spatial resolution to their management units would be most helpful for immediate decisions. Actionable data could be provided through consensus between scientists, peer review, limited ranges of variability, and an alignment of trends.

- Ecosystem managers further specified that decisions were not always driven by resourceprotection urgency, but by the development of management plans. In one situation discussed, those plans are currently being put in place and will determine policy and resource allocations for the next 30 years. This raised questions about what kinds of climate modeling projections would be actionable for a 30-year planning timeframe. For some climate variables, however, no ranges of variation across projections are currently available. Even where ranges have been quantified, there may not be a consensus on the range or the range may be too large to initiate any management actions. The questions regarding ways modelers could provide "actionable" information to managers were further complicated by the different confidences SD and DD models place in near-term and late 21st century projections. SD models provided more confident projections at nearer, mid-21st century timescales, whereas DD models provided more confident projections at the end of the $21 \mathrm{st}$ century, when the global warming signal was strongest. Certain management decisions, such as those concerning risk of extirpation of endangered species, may happen in time frames that are so near in the future that climate projection information about the late 21 st century would be nearly irrelevant.

In the third approach, participants suggested adapting management decisions to a range of scenarios based on storylines or plausible trajectories. Plausible future scenarios would be assembled from a variety of information sources, including, but not restricted to, downscaling outputs, and would represent uncertainties of model variables through the range of those scenarios. This was described as a "storyline" approach. Participants emphasized that 
downscaled outputs from SD and DD modeling were part of a larger body of information from which storylines, or "plausible trajectories" could be discerned for a range of scenarios. One participant supported this approach because it would allow all communities concerned with climate change to think more holistically about what the realm of climate futures might be. Information beyond SD and DD models is available (for example, historical trends, temperature maps, intermediate-DD models, ensembles of GCMs, and so on) and these multiple lines of evidence can be used to assess predictabilities. Agreement on predictability was another proposed means of approaching consensus on what these SD and DD models mean and this could be conveyed to managers and end users. Participants broadly agreed that climate scientists should consult managers and end users to determine what scales of association of cause and effect are useful in producing storylines and plausible future scenarios.

\section{Consultation between Managers and Climate Modelers Going Forward}

Participants recalled the indisputable observation that modelers and managers hold and use distinct understandings of the term "uncertainty." Modelers ask, "Why is something uncertain?" and managers ask, "How uncertain is it?" This difference was supported by Pacific RISA survey results. The survey, however, was unable to compare confidence levels of managers and modelers in the capacities of either type of climate modeling method because managers did not know or had no opinion. In order to increase users' understandings of the relative strengths of each downscaling model, modelers would need to translate their information in ways that accurately reflect their confidence in specific outputs. Further, the production of "actionable science" also posed a challenge to university scientists, whose training and practices were adapted towards communicating with other specialist scientists and not translating scientific findings for management purposes. A point of consensus was that communication using "uncertainty-based" expression should be replaced by "confidence-based" expression, which also aligns with substantial efforts being made by the Intergovernmental Panel on Climate Change (IPCC) to develop modes of expression for the complex climate change communication challenge.

The RISA pre-workshop survey highlighted a substantial need for better communication between climate scientists as knowledge developers and a broader audience of those implementing programs based on scientific results. Participants had experienced that process as idiosyncratic in which one "go[es] by feel" although some structured approaches were felt to help in that process. At a panel discussion just prior to the workshop, Jeremy Littell of the USGS (Alaska Climate Science Center) presented a schematic of the iterative process of communications between climate modelers and users (schematic from Ferguson and others 2014). Littell described a diagram of "adaptive management" that showed an iterative, codevelopment process in which climate projections would become more relevant to managers and users (fig. 1). Communication and collaboration between scientists and managers could reduce the distance between research questions and research needs and aid progress towards mutual understanding over time. The iterative process model underscores the importance of supporting intermediary and translation work on downscaling outputs, which was a recurrent theme during the workshop. 


\section{Narrowing the "gap" - clearly, repeatedly, iteratively....and competently. It takes a lot of capacity.}

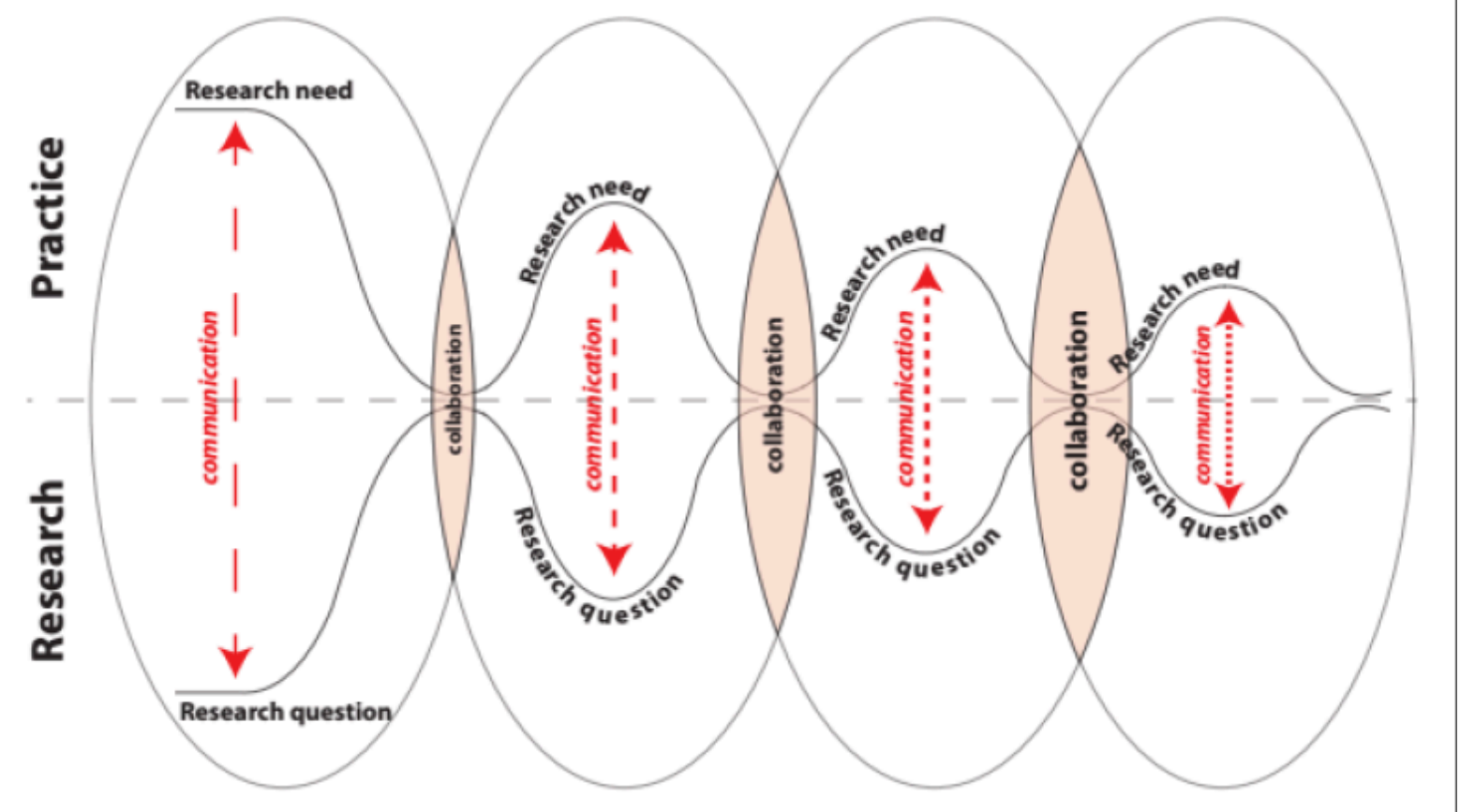

Figure 2. Diagram showing "adaptive management" of communication between climate modelers and users. Repeated interactions between research and practice reduce complexity of communication and increase collaboration, progressively making the adaptive management system more effective. From Ferguson and others (2014).

\section{Structured Discussion II: Best Science Practices, I}

The second structured discussion, "Best Science Practices I," was directed towards climate modelers' practices. The objective was to facilitate comparison of SD and DD model results and outputs through identification of a common framework, boundary conditions, and basic parameters for future modeling efforts. The agenda for this structured discussion included (1) identification of the best Coupled Model Intercomparison Project 5 (CMIP5), Representative Concentration Pathways (RCPs), and sets of downscaled variables (compared across SD and DD models) to represent Hawai' $i$ and (or) the greater Pacific region; (2) definition of temporal boundaries defining a historical climatology reference range and a future projection range; (3) agreement on a spatial scale and grid size for each high Hawai' $i$ island; and (4) standardization of data formats. Resource managers were anticipated to benefit from the systematic approach the discussion was intended to catalyze, because such coordinated modeling efforts would facilitate meaningful comparisons between different downscaled outputs.

At the outset, workshop organizers asked participants whether these were the ideal discussion topics. It was suggested that some were not the most productive topics to discuss. Participants raised questions about the value of comparing the downscaled models in the first place. Questions also were raised about the role of resource manager research needs in producing guidance for climate model outputs. An SD climate modeler opined that shifting temporal 
boundaries by 10 years would not affect model outputs and that the fact that this question was raised indicated that climate scientists had not communicated why some of the differences in their boundary conditions did not matter.

Participants also challenged assumptions of the discussion topics in "Best Science Practices I" by distinguishing between investigating the source of uncertainties, as contrasted with the source of differences, in model outputs. Some opined that examining the source of uncertainties would be more useful and that examination did not require standardization of methods. Others pointed out that one reason to ferret out differences between the models would be to reduce uncertainties based on inabilities to compare multiple downscaled products.

\section{Temporal Scales}

Resource managers stated that they were faced with the issue of timeframes or time horizons when climate change would factor into their decision-making. Climate modelers tended to have more confidence in projections towards the end of the 21 st century (2080-2100) because the signal of predicted changes owing to increased $\mathrm{CO}_{2}$ and other greenhouse gases (GHGs) are stronger than the noise of other climate factors. In the near term, projections might be dominated by ENSO and PDO signals, which would bury the GHG-attributed change. By contrast, natural variability in climate conditions occurs on 20-30 year timescales. Further out into the year 2080, a climate modeler explained, more technical certainty exists as to projections because natural variability would fade in relation to the anthropogenic signal.

For managers requiring near-term, mid-century predictions, a suggested use of climate models was the exploration of different sets of conditions and scenarios. This option was offered in response to the observation that end-of-century predictions concerned conditions possibly irrelevant to current decision-making. Some stated that certain irreversible resource decisions, however, could benefit from knowledge of projections 100 years in the future. For example, when land is rezoned to an urban zoning designation, it would be open to that use for the foreseeable future and water availability projections for 100 years from now would be relevant to that zoning decision.

Efforts to divorce temporal scales for climate modeling from management timeframes raised further issues concerning ways of conveying uncertainties associated with models using different temporal scales. Resource managers found information on uncertainty was useful towards implementing precautionary legal standards to their management efforts. Generally, participants noted that the breadth of uncertainty in climate projections could counsel a need to prepare for a wider variety of climate conditions.

\section{Spatial Scales}

Facilitators inquired as to whether climate modelers could agree on a common grid size for research purposes. Modelers noted that the spatial scale used was different for different islands. One modeling project had used a 3-km grid size for Hawai'i island projections and a 1$\mathrm{km}$ grid size for other Hawaiian Islands. Spatial scale requirements also differed across the questions to which the climate researchers were responding. An ecosystem impact modeler noted that a 1-km grid size would be useful for climate research, but a much smaller scale was needed to make climate data useful for modeling impacts on plant populations. Although the discussion initially had been directed towards climate modelers, participants pointed out that the ways modelers characterized uncertainty or identified best practices necessarily required a better understanding of how they interface with end-user communities. The potential for agreement on 
a common grid size was thus dependent on transformation and application contexts that extended beyond technical decisions made by different climate modeling researchers.

Identification of the best grid size or spatial scale raised cost-benefit considerations particularly pertinent to management decisions. Smaller grid sizes were generally considered better from a groundwater modeling perspective, but they came with a higher computational cost. When the cost for increasing resolution is considered, a larger grid size might suffice because one could interpolate information from a coarser model or models. Furthermore, at smaller scales, impacts from local factors, such as vegetation, may be more important than climate modeling factors. Participants noted that this perspective contrasted with the common belief that smaller grid sizes were necessarily indicative of more reliable and applicable outputs. Ecosystem managers attested to the limits of interpolating from SD and DD climate outputs for ecological models. They found standardizing either climate downscaling model to a 250 meter grid size caused the models to break down, presumably because this violated some assumptions of the respective models.

Some participants framed the question of the best resolution as identifying the asymptote at which better resolution does not provide different model outputs in the absence of regional or local information. Resource managers, it was suggested, could help to refine identification of research needs regarding grid size based on their decision-making needs. This prompted discussion of the overriding factors involved in natural resource management decision-making. Wildfire managers described their own need to develop a model for decision making and suggested a decision-making tool could help determine what level of resolution (or climate model grid size) is needed for different management decisions.

Finally, the choice of RCPs in different downscaled products arose in the context of this structured discussion. Several attendees challenged a proposal that no RCP other than $8.5^{6}$ described feasible climate futures. They stated the problem with assuming RCP 8.5-characterized climate futures is that human efforts to change their behaviors would be perceived as irrelevant and ineffectual at that rate of change. Instead, they opined it worthwhile to consider additional plausible pathways that reflect reductions in GHG concentrations (such as RCP 4.5), and thereby reduce the trajectory of change, inspiring natural resource managers to not give up. Others agreed with reinforcing a message that RCP 8.5 was not inevitable, stating, "We need to keep telling society that we have choices and options."

\section{Structured Discussion III: Applications of Current Products}

The second day of the workshop opened with presentations from freshwater, ecosystems, and wildfire managers (see Appendixes 5, 6, and 7). The third structured discussion concerning the application of current downscaling products followed these presentations. Resource managers were asked to provide the following in their presentations:

1. A statement of the resource management questions or needs - what they do and who they do it for;

1. Spatial scales of management needed for action and planning;

2. Temporal scales of management for action and planning;

\footnotetext{
${ }^{6}$ In other words, the IPCC's scenario that no change in GHG concentration trajectories will occur in coming decades.
} 
3. An identification of the most important environmental variables, parameters, or indices in their work;

4. A description of the way climate information is incorporated into resource management;

5. A definition of "normal" baseline conditions;

6. Contrasted implications of average versus extreme conditions for management; and

7. A description of the ways climate change would affect options available for resource management.

\section{Maui Water Case Study}

The "Application" structured discussion opened with consideration of specific collaborations directed towards applying SD and DD climate model projections to anticipated freshwater recharge on Maui. The Maui study produced a robust discussion about the limits of comparison, and the comparison of uncertainties in particular. In reference to SD modelers' quantification of the sources and magnitude of different environmental data and model uncertainties, some opined that different additional measures for observational uncertainties, such as satellite and station observations would be useful. Others recommended working on an ensemble product as a means to better represent uncertainty. In later discussions, SD modelers clarified that "uncertainty" in ensemble projections was gauged as an ensemble mean and not as the uncertainty within a specific model.

For application purposes, the pertinent question was: how would better-characterized uncertainties translate into management action items? All hoped a new generation of climate data could be more user-friendly. Towards this end, interaction with impact modelers and knowledge transformers would help climate modelers to better understand what is needed. Many recommended producing a range of future climate scenarios. Managers could select the futures they could plan for and impose a cost-benefit calculation to determine the scope of that planning.

Overall resource managers and modelers both opined that environmental measurements were more sparse than is ideal, and that a certain amount of interpolation and extrapolation from existing data would be needed. Resource managers tended to examine modeled climate futures based on the availability of data. For example, freshwater budget and ecosystem envelope models required temperature inputs, which were not provided by SD climate models. Resource managers further clarified that they scrutinized climate projections that would give rise to more protective measures. For example, freshwater managers stated they did not rely on wetter futures in order to increase water recharge rates. Wildfire managers likewise acted conservatively, and looked towards drier models as well because their management actions responded to drought. The range of resource protection responses indicated a danger in providing too few climate products or an uneven emphasis based on differences in availability of certain parameters across different modeling methods.

\section{Responses from Resource Managers}

Ecosystem impact modelers specifically indicated a need for temperature projections from SD models that could be incorporated into their ecosystem models. SD modelers promised to work towards providing such information. SD modelers further stated that failure to have provided that data previously could be attributed to differing priorities and that temperature modeling posed a less interesting research question - it was easy compared to the challenges of rainfall projections. Ecosystem modelers also stated they can work with trends and ranges of projections as long as the data provides "step changes" into the future, with consistent time steps, 
and does not consist of arbitrary points. Wildfire managers re-emphasized a desire for consensus between projections in order to inform management actions. Ecosystem managers stated they used "bits and pieces of different models" to mold them into information they could use. This reformulation of the data was needed because ecological models required data at different scales, periods, and parameterizations.

\section{Collaborative Transformation Paradigm of Climate Model Data Applications}

Several "missing pieces" were identified in workflow between climate models and their application: downscaling inconsistencies and disparities; characterizing and accounting for uncertainties; and transformation of downscaling data for use in subsequent applications via collaboration between scientists, transformers, and end users. Workshop participants discussed what might constitute best practices for communicating climate data to managers. One useful heuristic was an analogy of transformation between climate modelers, experts who develop ecological and natural resource impacts models, knowledge transformers who interact both with modelers and resource managers to analyze, repackage, and translate model output and other data into useable products, and resource managers. In this framework, the question for climate modelers was whether they could provide appropriate variables, time steps, and so on to drive the impact models. The question for managers is whether modeled data are dependable. The impact modelers and knowledge transformers are the nexus between these communities

A climate data translator participant offered that this approach had been applied in developing an impact model for Maui water budgets, but that it had not resolved a way for the climate data translators to communicate information effectively. Bringing modelers and managers into a technical conversation is one way forward.

Participants recommended a better elaboration of, and support for, the intermediate space between climate scientists and resource managers. Modeling-information translation is substantive work and an increased capacity, and planning to increase capacity, for this work is needed. A driving concern for many participants was identifying resources for this climate model output transformation work.

\section{"Loading Dock," "Concierge," and Other Data Dissemination Methods}

Participants' identified need for more capacity for translating modeling information was relevant to discussion of the limits of the "loading dock" model of disseminating basic climate modeling data. That is, climate modelers stated that merely making data publicly available had not ensured that the data were more widely used or used in the manner modelers intended. In discussing these problems, climate scientists and resource managers identified other relationships they could work through with respect to procuring funding. Such relationships could open new funding sources as agencies and university researchers generally receive funds from different sources.

In revisiting the question of optimal grid sizes for downscaled products in the context of resource manager-applications, participants again emphasized the utility of cost-benefit analyses and coordinating with managers to ensure data formats were usable. For ecosystem impact modelers, using climate modelers' new datasets posed little problem because their ecosystem models had been configured to readily integrate these new data. As indicated by the lack of temperature data from SD models, the specific kind of data needed for management actions also implicated issues of usability. 
The question of tailoring modeling outputs for different management needs raised issues of the ways in which climate modelers should respond to specific requests for different kinds of data. Participants explored benefits and limits of providing "concierge" services - on-demand delivery of custom climate projection outputs or datasets, or interpretations of existing products. Production of data at spatial scales, resolutions, and so on tailored to specific management needs, some stated, would not follow an organized inquiry and fail to contribute to a more comprehensive understanding of the interaction between models of impacts and models of climate. Additionally, some participants were concerned that concierge services would be costly and not useful, could potentially lead to inconsistent interpretation or messaging, and could possibly be unavailable to managers.

Provision of adequately scaled climate data, from which interpolation and upward aggregation could be conducted to develop climate impact information, was proposed as an alternative to concierge services. Another alternative model of concierge services was one of coproduction. Users approach modelers with a problem and modelers explain what answers climate data could provide. This guided approach was necessary to ensure users would not inappropriately use data.

\section{Storylines}

Inappropriate translation and use of climate projections emerged as a workshop concern. Beyond resource managers, who are endeavoring to grasp complexities and uncertainties of climate data, is a broader public whose "translator" is the general media. Participants voiced concern with a lack of ability to manage risks in situations in which the public and the media take partial or incomplete interpretations into forums that inform policy decisions. Freshwater resource managers noted that the Maui water climate projections had already been set into motion within the State of Hawai'i Commission on Water Resources Management (CWRM). These managers noted Maui Department of Water Supply was also relying on preliminary climate change projections of increased precipitation in wet areas and the location of Maui aquifer recharge areas in these wet areas.

Guidance in the form of storylines was proposed as a means to manage risks of the misuse of climate information. Storylines, some proposed, could be assembled from climate modeling outputs to define a range of climate scenarios. These scenarios could be compared with impact models in an experiment in which variables were coordinated. One participant noted the Coordinated Regional Climate Downscaling Experiment (CORDEX) has engaged projects requiring such coordination. CORDEX is an initiative of the World Climate Research Programme, whose purpose is "to advance and coordinate the science and application of regional climate downscaling partnerships." Managers stated that storylines most helpful for managers would include most likely scenarios. Managers and translators broadly agreed that a ranking or some kind of guidance about how to use information from the climate modelers would be helpful. Discussion of such confidence rankings ensued in the final structured discussion.

\section{Structured Discussion IV: Best Science Practices, II}

In the final structured discussion, participants ranked confidence levels for projected future climate conditions. The projected future climate conditions are organized by participants' agreements as to those confidence levels below, and a more detailed elaboration of discussions undergirding those agreements follows. 


\section{Participant Agreements}

\section{High Confidence:}

1. Air temperatures will rise

2. In coming decades, windward sides will become wetter during the wet season, with the trend most pronounced on Hawai' $i$ and Maui Islands

3. Sea-level will rise

4. Sea surface temperatures will rise

5. $\mathrm{pH}$ of surface waters will decrease (acidity will rise)

6. Anthropogenic climate change signal will be more pronounced by the end of century and beyond when compared with sources of inter-annual variability associated with natural climate variability modes such as ENSO

\section{Medium Confidence:}

7. Higher elevation areas will become warmer and drier

8. Increased occurrence of maximum temperature events

9. In coming decades, leeward sides will become drier in the dry season

10. The inversion layer will slightly decrease in height, and persistence (number of days) will increase

\section{Detailed Discussion of Confidence Agreements}

\section{High-Confidence Items:}

SD and DD modelers generally agreed to windward precipitation trends during the "wet" season in the mid-to-long term, but in the dry seasons, SD and DD projections diverged from each other. DD modelers noted Kaua' $i$ was exceptional as compared to other islands under RCP 8.5 scenarios. Topography effects on Hawai' $i$ and Maui Islands were stronger during the wet season than on Kaua'i, where westerly disturbances would be different. Thus, Kaua' $i$ was the noted exception to this high-confidence item.

Participants' agreement that anthropogenic climate change signals would be more pronounced at the end of the century, and that natural modes would dominate climate conditions in the near- to mid-century term. Participants noted climate change impacts in the form of new extreme weather events would occur in the mid-term and models disagreed as to how ENSO would operate in the near term.

All agreed that more environmental measurement and monitoring stations, and data generated from that monitoring, were needed to address a range of issues concerning uncertainties, calibration between models, and applications. It was highlighted that continuation of streamflow monitoring in areas with long-term records and reestablishment of monitoring in other island groups is critical to identifying significant trends, and the same can be said for other critical datasets such as ambient temperatures, sea level, and so on.

\section{Medium-Confidence Items}

Agreement that unprecedented high extremes in temperature would become more likely in the future met with only medium confidence in part because of a lack of comprehensive analyses of temperatures in Hawai' ${ }^{\prime}$. Also, historical trends showing an increase in daily mean 
temperatures could be disaggregated into daytime and nighttime phases. Daytime temperature increases, one SD modeler noted, were not as large as nighttime temperature increases. Daily mean temperature trends were thus distinguished from shifts towards increased incidences of extreme high temperatures.

Participants' DD models projected that inversion layer heights will decrease by approximately 20 meters and the frequency of occurrence of the inversion would increase by an estimated 8 percent. SD models are neutral on inversion layer projections, but their working hypothesis was in agreement with DD projections.

Participants agreed to medium confidence in projections that the leeward sides of islands would be drier at the end of the 21 st century. Upon inquiry into how to reconcile drying leeward and wetter windward patterns, DD modelers' physical explanation was that the upward motion in windward areas would strengthen downward motion in leeward areas.

DD and SD modelers agreed to a medium confidence level in projections that higher elevations would become warmer and drier. SD modelers thought that the mean trade-wind inversion would be more persistent and perhaps lower, which would leave higher elevations drier and warmer. SD and DD modelers observed faster changes at higher elevations and DD modelers noted their models showed a consistent change.

Other issues raised for potential consideration as participant agreements were not resolved. No committed agreement on the evapotranspiration trend signal was reached, nor was agreement reached on a projected number of trade-wind, as opposed to trade-wind inversion, days.

In addition to the above agreements on high- and medium-confidence items, other key agreements were met that may prove very useful as a foundation for ongoing work and discussions. General agreement was reached on the need for long-term monitoring and data collection and that a greater number of models, ranked in a hierarchy or along a continuum, are desirable.

\section{Wrap-Up: Downscaling Working Group}

The workshop concluded with a robust discussion of next steps that could be taken towards producing climate guidance and projections that are of maximal use to resource managers. Central to this discussion was identification of objectives and members of an informal Regional Downscaling Working Group. Participants discussed assembling two working groups, one comprising climate downscaling modelers, and the second composed of ecological impact modelers and knowledge transformers working directly with resource managers. A working group with a broader objective was preferred and should conduct "check backs" with impact modelers and knowledge transformers. A simple fact sheet, as opposed to a newsletter, for conducting these check backs and updating the wider community of those interested in climate products, was suggested as a product.

Some modelers suggested the working group could coordinate experimenting to better utilize capacity and could also develop plausible mechanisms for differences observed. Other modelers opined that their participation in the working group be limited to improving the translation of, and communication about, their own data to make it more usable for managers and other end users.

The working group would serve several purposes, including improving downscaling, better characterizing uncertainties, and building trust among the climate modeling communities contributing to a more structured comparison of climate downscaling products and conducting 
internal discussions of climate modeling research issues before releasing products to decisionmaking communities and other end users. Resource managers emphasized the value of agreement among climate modelers on certain projections and levels of confidence. This consensus from the scientific community could be actionable for management decision-making purposes.

The working group was tasked to refine the following enunciated objectives:

1. To extend and retool the Pacific RISA survey to include the impact modeling and knowledge transformation communities;

2. To prioritize the development of coordinated experiments using comparable conditions, domains, timescales, RCPs, and so on;

3. To identify areas of consensus and confidence in various climate models and projections; and

4. To improve modeling for use by resource managers.

Dr. Tom Giambelluca (http:/www.geography.hawaii.edu/faculty/tomgiambelluca.html) agreed to serve as the working group convener. Dr. Giambelluca is familiar with the technical details of SD and DD climate modeling and supported open discussions oriented towards understanding both methodologies, bringing out the best possible science, and making meaningful outputs.

Finally, participants identified a need for Hawai'i modelers and the working group to recognize they were not working in a vacuum. Recommendations included keeping abreast of new developments in national, regional, and international climate modeling projects and identifying gaps that the Hawai'i modeling project could help to fill. Participants identified missing sectors, such as marine sciences, agriculture, energy, infrastructure, and transportation planning, which are also in need of climate projections. 


\section{Selected References}

Dubayah, R., and Rich, P.M., 1995, Topographic solar radiation models for GIS: International Journal of Geographical Information Systems, v. 9, no. 4, p. 405-419.

Elison Timm, O., Giambelluca, T.W., and Diaz, H.F., 2015, Statistical Downscaling of Rainfall Changes in Hawai'i based on the CMIP5 Global Model Projections: Journal of Geophysical Research-Atmospheres, v. 120, no. 1, p. 92-112, doi:10.1002/2014JD022059.

Ferguson, D.B., Rice, J.L., and Woodhouse, C.A., 2014, Linking environmental research and practice-Lessons from the integration of climate science and water management in the Western United States: University of Arizona Climate Assessment for the Southwest, Handbook, 19 p.

Leiserowitz, A., Maibach, E., Roser-Renouf, C., Feinberg, G., \& Rosenthal, S., 2015, Climate change in the American mind-March, 2015: New Haven, Conn., Yale University and George Mason University, Yale Project on Climate Change Communication.

Newman, A.J., Clark, M.P., Winstral, A., Marks, D., and Seyfried, M., 2014, The use of similarity concepts to represent subgrid variability in land surface models-Case study in a snowmelt-dominated watershed: Journal of Hydrometeorology, v. 15, no. 5, p. 1717-1738.

Norton, C.W., Chu, P.-S., and Schroeder, T.A., 2011, Projecting changes in future heavy rainfall events for Oahu, Hawaii-A statistical downscaling approach: Journal of Geophysical Research—Atmospheres, v. 116, no. D17, doi:10.1029/2011JD015641.

Thornton, P.E., Running, S.W., and White, M.A., 1997, Generating surfaces of daily meteorological variables over large regions of complex terrain: Journal of Hydrology, v. 190, no. 3, p. 214-251.

Zhang, C., Wang, Y., Lauer, A., and Hamilton, K., 2012, Configuration and Evaluation of the WRF Model for the Study of Hawaiian Regional Climate: Monthly Weather Review, v. 144, no. 7, doi:10.1175/MWR-D-11-00260.1. 


\section{Appendixes 1-8}

Appendixes are available online only as PDF (.pdf) and Excel (.xlsx) files at http://dx.doi.org/10.3133/ofr20161102.

Appendix 1. "Review of RISA Survey: Insights Learned Through Using Downscaled Climate Products" by Victoria Keener

Appendix 2. "Island Downscaling Resources Matrix" model descriptions

Appendix 3. "Presentation on Statistical Downscaling" by Oliver Elison Timm

Appendix 4. "Dynamical Downscaling" by Yuqing Wang

Appendix 5. "The Climate Change Conundrum: A Water Resource Management Perspective" by Lenore Ohye

Appendix 6. "Estimating Climate-Change Impacts on Groundwater Recharge for the Island of Maui, Hawai' i " by Alan Mair

Appendix 7. "Drought and Fire in Hawai'i and the US Affiliated Pacific Islands" by Christian Giardina and Michelle Mansker

Appendix 8. "Application Perspective Case Studies-Hawaiian Species and Habitat Conservation in a shifting climate" by Lucas Fortini, Sierra McDaniel, Rick Camp, and Jim Jacobi 


\section{Appendix Abbreviations}

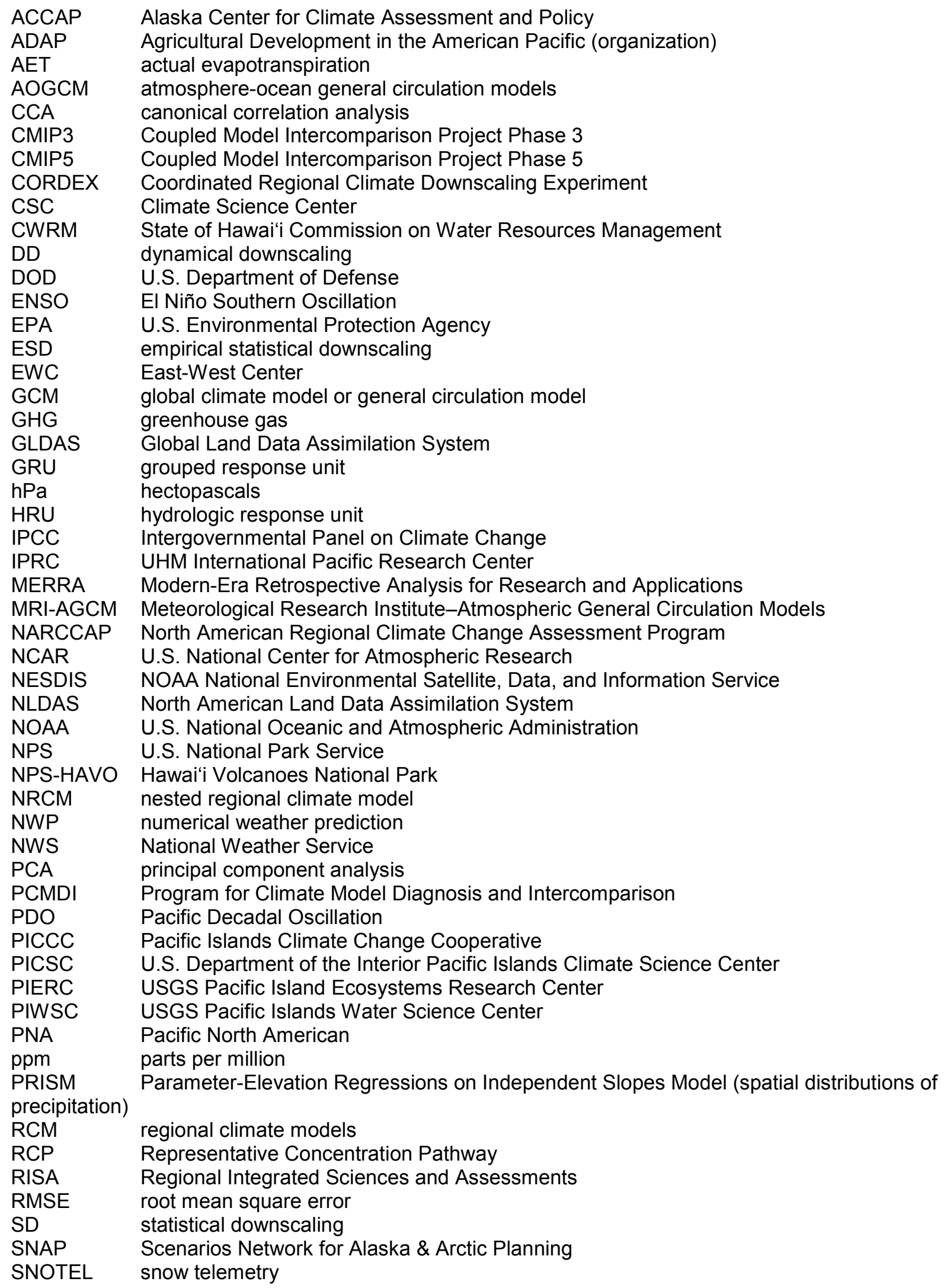




$\begin{array}{ll}\text { SST } & \text { sea surface temperature } \\ \text { SVATs } & \text { Surface Vegetation Atmosphere Transfer Schemes } \\ \text { STARDEX } & \text { Statistical and Regional Dynamical Downscaling of Extremes for European regions } \\ \text { TC } & \text { tropical cyclone } \\ \text { UHM } & \text { University of Hawai'i at Mānoa } \\ \text { USDA } & \text { U.S. Department of Agriculture } \\ \text { IPIF } & \text { U.S. Forest Service Institute of Pacific Islands Forestry } \\ \text { USGS } & \text { U.S. Geological Survey } \\ \text { USAPI } & \text { United States Affiliated Pacific Islands } \\ \text { USHCN } & \text { U.S. Historical Climatology Network (formerly National Climatic Data Center) } \\ \text { WCRP } & \text { World Climate Research Program (CORDEX database) } \\ \text { WGCP } & \text { Working Group on Coupled Modeling } \\ \text { WNP } & \text { Western North Pacific } \\ \text { WRF } & \text { Weather Research and Forecasting Model }\end{array}$


ISSN 2331-1258 (online)

http://dxhttp://dx.doi.org/

10.3133/ofr20161102 